\title{
Elucidating the Construct Validity of the Psychopathic Personality Inventory Triarchic Scales
}

ARTICLE in JOURNAL OF PERSONALITY ASSESSMENT · JULY 2015

Impact Factor: 1.84 · DOI: 10.1080/00223891.2014.962654 · Source: PubMed

CITATIONS

3

3 AUTHORS:

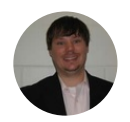

Martin Sellbom

University of Otago

124 PUBLICATIONS 1,800 CITATIONS

SEE PROFILE

Laura E Drislane

Florida State University

19 PUBLICATIONS 141 CITATIONS

SEE PROFILE
READS

182
Dustin B Wygant

Eastern Kentucky University

44 PUBLICATIONS 747 CITATIONS

SEE PROFILE 
This article was downloaded by: [Florida State University]

On: 22 October 2014, At: 06: 27

Publisher: Routledge

Informa Ltd Registered in England and Wales Registered Number: 1072954 Registered office: Mortimer House, 37-41 Mortimer Street, London W1T 3J H, UK

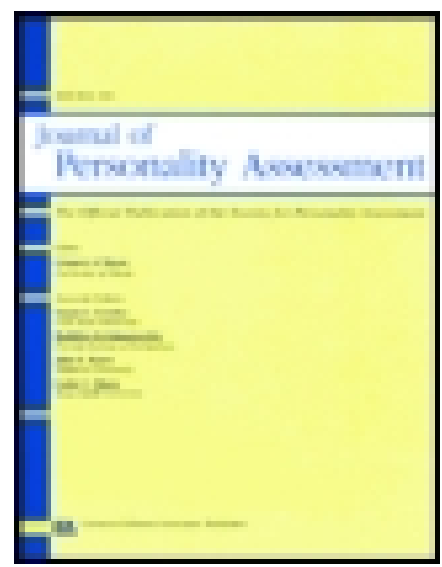

\title{
J ournal of Personality Assessment
}

Publication details, including instructions for authors and subscription information: http:// www.tandfonline.com/loi/hjpa20

\section{Elucidating the Construct Validity of the Psychopathic Personality Inventory Triarchic Scales}

\author{
Martin Sellbom ${ }^{a}$, Dustin B. Wygant ${ }^{b} \&$ Laura E. Drislane \\ ${ }^{a}$ Research School of Psychology, The Australian National University \\ ${ }^{b}$ Department of Psychology, Eastern Kentucky University \\ ${ }^{c}$ Department of Psychology, Florida State University \\ Published online: 17 Oct 2014.
}

To cite this article: Martin Sellbom, Dustin B. Wygant \& Laura E. Drislane (2014): Elucidating the Construct Validity of the Psychopathic Personality Inventory Triarchic Scales, J ournal of Personality Assessment, DOI: 10.1080/ 00223891.2014.962654

To link to this article: http:// dx. doi.org/ 10.1080/00223891.2014.962654

\section{PLEASE SCROLL DOWN FOR ARTICLE}

Taylor \& Francis makes every effort to ensure the accuracy of all the information (the "Content") contained in the publications on our platform. However, Taylor \& Francis, our agents, and our licensors make no representations or warranties whatsoever as to the accuracy, completeness, or suitability for any purpose of the Content. Any opinions and views expressed in this publication are the opinions and views of the authors, and are not the views of or endorsed by Taylor \& Francis. The accuracy of the Content should not be relied upon and should be independently verified with primary sources of information. Taylor and Francis shall not be liable for any losses, actions, claims, proceedings, demands, costs, expenses, damages, and other liabilities whatsoever or howsoever caused arising directly or indirectly in connection with, in relation to or arising out of the use of the Content.

This article may be used for research, teaching, and private study purposes. Any substantial or systematic reproduction, redistribution, reselling, loan, sub-licensing, systematic supply, or distribution in any form to anyone is expressly forbidden. Terms \& Conditions of access and use can be found at http:// www.tandfonline.com/page/terms-and-conditions 


\title{
Elucidating the Construct Validity of the Psychopathic Personality Inventory Triarchic Scales
}

\author{
Martin Sellbom, ${ }^{1}$ Dustin B. Wygant, ${ }^{2}$ ANd Laura E. Drislane ${ }^{3}$ \\ ${ }^{1}$ Research School of Psychology, The Australian National University \\ ${ }^{2}$ Department of Psychology, Eastern Kentucky University \\ ${ }^{3}$ Department of Psychology, Florida State University
}

\begin{abstract}
This study sought to replicate and extend Hall and colleagues' (2014) work on developing and validating scales from the Psychopathic Personality Inventory (PPI) to index the triarchic psychopathy constructs of boldness, meanness, and disinhibition. This study also extended Hall et al.'s initial findings by including the PPI Revised (PPI-R). A community sample $(n=240)$ weighted toward subclinical psychopathy traits and a male prison sample $(n=160)$ were used for this study. Results indicated that PPI-Boldness, PPI-Meanness, and PPI-Disinhibition converged with other psychopathy, personality, and behavioral criteria in ways conceptually expected from the perspective of the triarchic psychopathy model, including showing very strong convergent and discriminant validity with their Triarchic Psychopathy Measure counterparts. These findings further enhance the utility of the PPI and PPI-R in measuring these constructs.
\end{abstract}

Psychopathy is a serious personality disorder marked by deficits in affective processing, interpersonal relations, and dysfunctional behavior (Hare \& Neumann, 2008). Patrick, Fowles, and Krueger (2009) proposed the triarchic model of psychopathy as a means of integrating persisting fundamental themes of current and historic conceptualizations and measurement modalities of the disorder. The triarchic model of psychopathy characterizes the disorder along three interrelated yet distinctive phenotypic dimensional domains of boldness (social dominance, low stress reactivity, and thrill-adventure seeking), meanness (callousness, interpersonal detachment, exploitativeness), and disinhibition (impulsivity, poor selfregulation, low frustration tolerance; Patrick, Drislane, \& Strickland, 2012). Empirical support has already begun to accumulate for this model (e.g., Drislane, Patrick, \& Arsal, 2014; Patrick, 2010; Sellbom \& Phillips, 2013).

Patrick (2010) developed the Triarchic Psychopathy Measure (TriPM) to directly assess the triarchic domains. Subsequent to its release, several studies had reported evidence supporting the convergent and discriminant validity of the three scale scores in undergraduate (Drislane et al., 2014; Marion et al., 2013; Sellbom \& Phillips, 2013), community (Anderson, Sellbom, Wygant, Salekin, \& Krueger, in press; Strickland, Drislane, Lucy, Krueger, \& Patrick, 2013), and correctional (Patrick, 2010; Sellbom \& Phillips, 2013; Stanley, Wygant, \& Sellbom, 2013) samples based on their absolute and relative associations with a broad range of other psychopathy measures and conceptually relevant personality traits.

Patrick and colleagues (Drislane et al., in press; Hall et al., 2014; Patrick, 2010; Skeem, Polaschek, Patrick, \& Lilienfeld, 2011) have also advocated that the three triarchic domains

Received June 8, 2014; Revised August 24, 2014.

Address correspondence to Martin Sellbom, Research School of Psychology, The Australian National University, Building 39, Canberra, ACT 0200, Australia; Email: martin.sellbom@anu.edu.au could be operationalized in various assessment instruments to allow for more expansive research. Although developed to characterize major themes discussed in the psychopathy literature specifically, the triarchic model phenotypes are believed to reflect basic dispositional tendencies rooted in neurobiology that underlie a range of psychopathology (e.g., other externalizing problems, disorders marked by dysfunction of the defensive motivational system, and other personality disorders characterized by deficient affiliation). As such, these traits are hypothesized to be embedded within a number of existing assessment instruments not originally developed to index the triarchic model constructs.

To date, published research has shown promising efforts with both the Youth Personality Traits Inventory (Drislane et al., in press) and the Psychopathic Personality Inventory (PPI; Lilienfeld \& Andrews, 1996; see also Hall et al., 2014). The PPI, and its revised version, the PPI-R, is a widely researched instrument for indexing psychopathy from a dimensional trait approach. Hall et al. (2014) used a consensus-based rating approach to select items for inclusion in the PPI-Triarchic (PPI-Tri) scales. Initially, five doctoral students rated individual items from the 187-item PPI in relation to their conceptual proximity to the triarchic domains. Initial item selection was followed up by additional statistical refinement analyses to maximize internal consistency as well as relative convergence and divergence for each item for their target scales. Hall and colleagues further examined external correlates of the PPI-Tri scales in undergraduate and forensic samples, and the scales exhibited promising convergent and discriminant validity. More specifically, PPI-Boldness was preferentially associated with TriPM Boldness; Psychopathy Checklist-Revised (PCL-R; Hare, 2003) scores reflecting interpersonal deficits; and personality traits of social potency, stress immunity, and fearlessness. PPI-Meanness was primarily associated with TriPM Meanness; psychopathy criteria reflecting callousness egocentricity, affective detachment, and antisocial behavior; scores on antisocial personality disorder measures; and personality traits indicating detachment, 
aggression, and antagonism. Finally, PPI-Disinhibition was preferentially related to psychopathy criteria centered on impulsivity, sensation seeking, and antisocial lifestyle. This PPI scale was also meaningfully associated with a range of measures indexing antisocial personality disorder, conduct disorder, aggression, alienation, and stress reactivity.

The PPI-Tri scales pose a number of strengths relative to the original PPI factor structure. Traditionally, investigators have evaluated the PPI and PPI-R in terms of two higher order factors, Fearless Dominance (FD; encompassing the Social Potency, Stress Immunity, and Fearlessness subscales) and Self-Centered Impulsivity (SCI; encompassing the Carefree Nonplanfulness, Impulsive Nonconformity, Machiavellian Egocentricity, and Blame Externalization subscales; Benning, Patrick, Hicks, Blonigen, \& Krueger, 2003). The remaining PPI and PPI-R subscale, Coldheartedness, does not load appreciably on either of the higher order factors, and is thus either omitted from analyses or treated as a stand-alone scale. The stability of this factor structure has been criticized by some (Neumann, Malterer, \& Newman, 2008), and the role of PPI-FD in the nomological network of psychopathy has been the focus of considerable debate in recent years (Lilienfeld et al., 2012; Miller \& Lynam, 2012). The PPI-Tri scales, by contrast, represent a reconfiguration of the PPI item set, using only those items deemed to be most central to the triarchic model constructs (i.e., omitting construct-irrelevant variance that might be captured by remaining PPI items). Crucially, the PPI-Tri scales also better distinguish general externalizing proneness from callous aggressive tendencies through separate Disinhibition and Meanness scales, respectively. By combining items from the Coldheartedness and Machiavellian Egocentricity subscales (among other items), PPI-Tri Meanness more fully captures the manipulative, antagonistic interpersonal style characteristic of psychopathy than Coldheartedness alone; likewise, this reconfiguration allows for a purer measure of disinhibitory proneness than PPI-SCI, by omitting variance in the Machiavellian Egocentricity subscale more relevant to meanness. From a nosology standpoint, meanness and disinhibition are highlighted as important, separable symptomatic components of both childhood conduct disorder (CD) and adult antisocial personality disorder (ASPD) in the most recent edition of the Diagnostic and Statistical Manual of Mental Disorders (5th ed. [DSM-5]; American Psychiatric Association, 2013). Specifically, CD now includes a "limited prosocial emotions" specifier indicative of callous-unemotional traits akin to the adult concept of meanness. In the alternative dimensional system for assessing personality disorders in Section III of DSM-5, ASPD is characterized by traits specified within the domains of antagonism (i.e., meanness) and disinhibition. Further, the psychopathic traits specifier for ASPD closely indexes the features assessed by PPI-Tri Boldness. Thus, the PPI-Tri scales allow for clearer evaluation of distinguishable traits highlighted in historic and contemporary accounts of psychopathy and codified in the DSM.

This study sought to extend the validity research on the PPI and PPI-R Triarchic scales. As previously stated, the PPI and PPI-R are the most frequently used self-report instruments in psychopathy research and are featured extensively in a large number of archival databases for which it would now be possible to evaluate psychopathy from the perspective of the triarchic model of psychopathy. Unlike the TriPM, which has not yet been used for clinical purposes, the PPI-R is normed and accessible to clinicians for applied use. Thus, triarchic scales for the PPI-R would allow clinicians to incorporate this conceptualization of psychopathy into forensic and clinical assessment of offenders and patients (e.g., risk assessment, treatment planning; Patrick et al., 2012). This study also offers important extensions of Hall et al. (2014) via the use of a prison sample and a community sample weighted for subclinical psychopathy traits as well as a range of additional external criteria conceptually relevant to the triarchic constructs (e.g., fearlessness for Boldness, low empathy for Meanness, and antisocial behavior for Disinhibition). In addition, Hall et al. did not examine the validity of the PPI-R Triarchic scales, but did provide item sets, so this is the first study to formally evaluate these scales. The shaded portion of Table 1 includes an indication of hypothesized findings based on the construct validity research available on the triarchic scales more broadly (e.g., Drislane et al., 2014; Hall et al., 2014; Sellbom \& Phillips, 2013; Stanley et al., 2013).

\section{Participants and Procedures}

\section{METHOD}

Community Sample. This sample consisted of 140 male and 100 female community-dwelling individuals in central Alabama who were recruited for subclinical psychopathic traits via advertisement for "adventurous, fearless, charming, and carefree people who've led exciting lives. Are you are the kind of person who'd do almost anything for a dare? Are you good at looking out for number one as well as handling other people?" This method was based on previous research successfully using this form of recruitment (Belmore \& Quinsey, 1994; DeMatteo, Heilbrun, \& Marczyk, 2006; Raine, Lencz, Bihrle, LaCasse, \& Colletti, 2000; Widom, 1977; Widom \& Newman, 1985). Individuals were administered the research battery individually by extensively trained doctoral students, and were paid $\$ 75$ for their participation. Participants were 55\% White, 36\% African American, and $9 \%$ of other or mixed ethnicity. They had a mean age of 26.9 $(S D=10.1)$, ranging from 18 to 75 , and an average of 14.4 $(S D=2.2)$ years of education. See Anderson et al. (in press) for more details about procedures and recruitment success for a subset of this sample.

Prison Sample. This sample consisted of 160 male inmates recruited from a medium-security prison in Kentucky. Study materials were administered individually by a trained research assistant. The mean age of participants was 34.2 (SD $=9.6)$ with mean education of 11.9 years $(S D=1.2)$. The sample was predominantly White (56\%), with $40 \%$ identifying themselves as African American and the remaining inmates (4\%) identifying themselves as coming from other racial or ethnic groups. Sixty percent of the current sample was incarcerated for violent offenses (including $22 \%$ of the total sample for homicide-related offenses), $24 \%$ for sexual offenses, and $27 \%$ for drug-related offenses, among others.

\section{Measures}

Psychopathic Personality Inventory. Community participants were administered the PPI (Lilienfeld \& Andrews, 
Table 1.-Zero-order correlations and multiple regression analyses for the PPI Triarchic Scales.

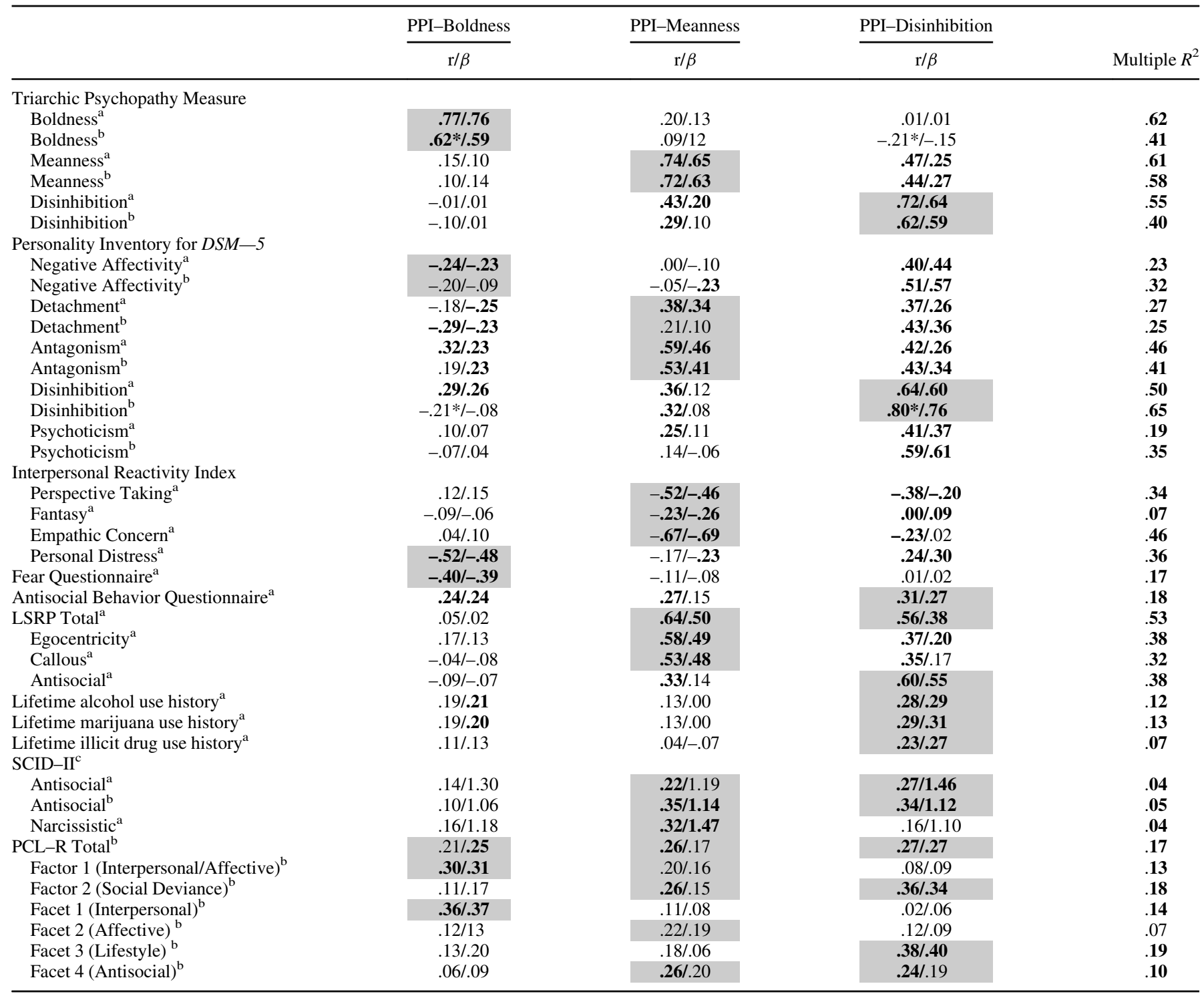

Note. Shaded entries denote hypothesized relationships. Bolded zero-order correlation coefficients, standardized beta weights, and multiple $R^{2}$ are significant at the .002 level in the community sample (.05/23) and at the .003 level in the prison sample (.05/16). PPI = Psychopathic Personality Inventory; LSRP = Levenson Self-Report Psychopathy Scale; SCID-II $=$ Structured Clinical Interview for DSM-IV Axis II Personality Disorders; PCL $-\mathrm{R}=$ Psychopathy Checklist - Revised

${ }^{a}$ Community sample. ${ }^{b}$ Prison sample. ${ }^{c}$ SCID-II variables are count scores and therefore not normally distributed; as such, negative binomial regression models were estimated with McFadden pseudo- $R^{2}$ values reported.

*Significant difference in correlation magnitude across the two samples computed using Fisher's $z$.

1996; Lilienfeld \& Widows, 2005), whereas the prison sample was administered the PPI-R. The PPI and PPI-R are 187- and 154-item self-report questionnaires designed to assess psychopathic personality traits. Both versions yield one total score, three factor scores-Fearless-Dominance, Impulsive Antisociality (SCI on the PPI-R), and Coldheartedness (based on one single subscale) — and scores from eight subscales. In addition to fewer items, the PPI-R differs from the original version of the instrument in terms of (lower) reading level and omission of idiom-specific references. Thus, although the content of the items is largely the same across both versions, the specific wording varies for many of the items. Approximately $20 \%$ of the items are identical across the PPI and PPI-R, $45 \%$ of items differ by one or two words, and $35 \%$ of items differ substantially in wording, but not in meaning. This investigation focused on three scales designed to index the triarchic constructs of Boldness, Meanness, and Disinhibition (Hall et al., 2014). PPI-Boldness is made up of items from the Fearlessness, Social Potency, and Stress Immunity subscales of the PPI; PPI-Meanness is composed of items from Coldheartedness, Machiavellian Egocentricity, and Fearlessness; and PPI-Disinhibition includes items from the Carefree Nonplanfulness, Blame Externalization, Impulsive Nonconformity, Machiavellian Egocentricity, and Stress Immunity subscales of the PPI. In our study samples, internal consistencies for these three scales were $.71 / .84$ (correctional/community) for Boldness, .77/.79 for Meanness, and $.76 / .74$ for Disinhibition. 
Triarchic Psychopathy Measure. The TriPM (Patrick, 2010) is a 58-item self-report inventory of psychopathy that was administered in both samples. Although a total score can be computed for the TriPM, the primary focus of the inventory is on assessing psychopathy in terms of three distinguishable, albeit modestly correlated, dimensions of psychopathy: Boldness, Meanness, and Disinhibition. Patrick (2010) provided data regarding the differential correlates of these scales. The TriPM has exhibited good construct validity in both university (Drislane et al., 2014; Sellbom \& Phillips, 2013) and correctional (Sellbom \& Phillips, 2013; Stanley et al., 2013) samples. Each of the three scales met the cutoff for acceptable internal consistencies $(\alpha \mathrm{s}=.76-.88)$ across both samples.

Personality Inventory for DSM-5. The Personality Inventory for DSM-5 (PID-5; Krueger, Derringer, Markon, Watson, \& Skodol, 2012) is a 220-item self-report inventory developed to index the five $D S M-5$ Section III personality domains and their respective facets. It was administered in both samples. The factor structure and other external construct validity evidence for this measure has been documented in numerous studies (e.g., Anderson et al., 2013; Hopwood, Thomas, Markon, Wright, \& Krueger, 2012; Sellbom, Anderson, \& Bagby, 2013; Thomas et al., 2013). We used the PID5 domain scores in this study; internal consistencies in our study samples (Cronbach's alpha) ranged from .89 (Disinhibition in the prison sample) to .95 (Psychoticism in the community sample).

Psychopathy Checklist-Revised. The PCL-R (Hare, 2003 ) is a 20 -item clinician rating scale for psychopathy. The PCL-R includes a semistructured clinical interview and review of the participant's institutional record. Following the interview and file review, the researcher rates each participant on a scale of 0 (not present), 1 (maybe, or occasionally, present), and 2 (definitely present) for each item, yielding a possible range of scores of 0 to 40 . Previous research studies have reported excellent interrater reliabilities of greater than .90 for the PCL-R (Hare, 2003). Twelve percent of the sample was independently rated by two graduate research assistants to calculate interrater reliability. The reliability for the Total score of the PCL-R was good (intra-class correlation $[\mathrm{ICC}]=.93$ ). In addition to a Total score, the PCL-R yields two factor scores, Factor 1 (Affective/Interpersonal) and Factor 2 (Social Deviance), and four facets, 1 (interpersonal), 2 (affective), 3 (lifestyle), and 4 (antisocial). The PCL-R was only administered in the prison sample. The first and second authors, both licensed clinical psychologists with specialized training in psychopathy assessment (e.g., completed Darkstone Research Group training on the PCL-R), provided direct clinical supervision for all PCL-R ratings, which were completed by trained graduate research assistants. Graduate research assistants also completed formal PCL-R training via various workshops.

Structured Clinical Interview for DSM-IV Axis II Disorders. The Structured Clinical Interview for DSM-IV Axis II Disorders (SCID-II; First, Gibbon, Spitzer, Williams, \& Benjamin, 1997) is a structured interview commonly used to reliably assess $D S M-I V$ personality disorder criteria. Available data indicate good interrater reliability for ASPD and narcissistic personality disorder (NPD) with this instrument with
ICC ranging from .80 (Lobbestael, Leurgans, \& Arntz, 2011) to .98 (Maffei et al., 1997). This study used the SCID-II questions as a dimensional symptom count ranging from 0 to 8 for ASPD (the seven adult criteria and evidence of conduct disorder prior to age 15) in both samples and 0 to 9 for NPD in the community sample only.

Levenson Self-Report Psychopathy Scale. The Levenson Self-Report Psychopathy Scale (LSRP; Levenson, Kiehl, \& Fitzpatrick, 1995) is a 26-item self-report measure designed to assess the defining personality and behavioral features of psychopathy. It was administered in the community sample. Recent work has shown evidence for a three-factor model reflecting egocentricity, callous, and antisocial proclivities (e.g., Sellbom, 2011). Internal consistencies ranged from .70 (Callous and Antisocial) to .83 (Egocentricity) in the current sample.

Antisocial Behavior Questionnaire. The Antisocial Behavior Questionnaire (ABQ; Sellbom \& Verona, 2004; Wall, Sellbom, \& Goodwin, 2013) is a 16-item self-report inventory inspired by other questionnaires to reliably assess delinquency and antisocial conduct in juveniles and college students, respectively (Hirschi, Hindelang, \& Weis, 1980; Lynam, Whiteside, \& Jones, 1999). Our version lists 16 behaviors that would be considered "criminal" in nature, including theft, assault, vandalism, drunk driving, fraud, drugrelated offenses, and domestic violence. Participants respond as to whether they had acted in the manner described in each question on a scale of three response options: 1 (no), 2 (yes, but only once), and 3 (yes, more than once). The ABQ has been found to correlate with the PPI Total $(r=.49-.63)$ and PPI Impulsive-Antisociality $(r=.52-.69)$ scores (Sellbom \& Verona, 2004; Sellbom et al., 2012; Wall et al., 2013). Internal consistency in this study was .84; it was only administered in the community sample.

The Interpersonal Reactivity Index. The Interpersonal Reactivity Index (IRI; Davis, 1983) is a 28-item measure of dispositional empathy that has been used in previous psychopathy research (e.g., Alterman, McDermott, Cacciola, \& Rutherford, 2003; Stanley et al., 2013). It consists of four separate, seven-item scales that tap particular facets of empathy (empathic concern, personal distress, perspective taking, and fantasy [imaginative transposition of feelings onto fictional others]). Internal consistencies in this study ranged from .70 (Fantasy) to .75 (Perspective Taking). It was only administered in the community sample.

Fear Questionnaire. The Fear Questionnaire (FQ; Marks \& Mathews, 1979) asks participants to rate 15 situations (e.g., "Going into crowded shops," "Large open spaces," or "Sight of blood") on a scale ranging from 0 (would not avoid it) to 8 (always avoid it). These ratings are used to generate scores on three subscales: Social Phobia, Agoraphobia, and Blood/ Injury Phobia; a total score indicating general fearfulness was used in this study. The structure of the FQ as well as its convergent and discriminant validity in differentiating various symptoms of anxiety disorders has been established (e.g., Oei, Moylan, \& Evans, 1991). Internal consistency in this study for 
the FQ Total score was .85. It was only administered in the community sample.

Background Interview. Each of the participants in the community sample completed an extensive interview focusing on various psychosocial background variables, including questions about education, employment, medical history, mental health, substance use, and legal history. For this study, we focused on lifetime ratings of alcohol and drug use based on a rating scale from 0 (no use) to 4 (definitely abuse). Alcohol and marijuana use were utilized as separate scores, whereas illicit drug use (cocaine, heroin, methamphetamine, etc.) were averaged into a composite score.

\section{RESULTS}

We first calculated intercorrelations between the PPI-Tri scales. These were .09 (community) and .03 (prison) for PPIBoldness and PPI-Meanness; -.05 (community) and -.17 (prison) for PPI-Boldness and PPI-Disinhibition; and .35 (community) and .32 (prison) for PPI-Meanness and PPI-Disinhibition. These are very similar to those reported in Hall et al.'s (2014) forensic and student samples.

For external criterion analyses, we estimated zero-order correlations between PPI-Triarchic scales and external criteria in both samples. Moreover, to further elucidate the relative and unique correlates for each PPI-Triarchic scale, we regressed each of the external criteria onto the three PPI scale scores. These models were estimated via ordinary least squares for all criteria, except the SCID symptom counts for which negative binomial models were used. For the former models, all criterion variables met standards for normal distribution and homoscedasticity, whereas the count distributions were best estimated via a negative binomial model because the variances were overdispersed relative to the means. Because of the large number of external criteria for each PPITriarchic scale and thus to control for family-wise error, we used Bonferroni-corrected alphas of .002 (.05/23 criteria) in the community sample and .003 (.05/16 criteria) in the prison sample. Table 1 shows all correlation and standardized regression coefficients for each model.

\section{PPI-Boldness}

As expected, PPI-Boldness evinced a large effect size association with TriPM Boldness in both samples, and was weakly to uncorrelated with the other TriPM scales, which is consistent with the findings of Hall et al. (2014). The correlation between PPI-Boldness and TriPM Boldness was stronger in the community sample than the prison sample (Fisher's $z=$ $2.87, p=.004)$. In terms of other psychopathy criteria, PPIBoldness was associated with the largest effect size in terms of predicting PCL-R Factor 1 and Facet 1 capturing the core interpersonal and social dominance qualities of the disorder. This PPI scale was not significantly associated with any of the LSRP scales, as expected, given the latter's lack of coverage of this psychopathy domain (see Drislane et al., 2014; Sellbom \& Phillips, 2013). With regard to personality traits, PPIBoldness scores were moderately associated with low negative affectivity and low detachment, but also had significant associations with high antagonism and disinhibition, especially in the community sample (Fisher's $z=4.97, p<.001$ for PID-5 Disinhibition). Whereas the former are consistent with previous research, the latter are likely a reflection of specific associations with risk taking (Disinhibition) and grandiosity (Antagonism), which are common correlates of this psychopathy construct (Anderson et al., in press; Sellbom \& Phillips, 2013; Strickland et al., 2013). Interestingly, PID-5 Antagonism was uniquely predicted by all three of the PPI-Triarchic scales (albeit most strongly by PPI-Meanness), which supports some scholars' contention that antagonism is a core component of psychopathy (see, e.g., Lynam \& Derefinko, 2006). Furthermore, PPI-Boldness was associated with the largest effect size in terms of predicting low scores on the FQ and IRI Personal Distress, which indicates low emotional reactivity reflected in this psychopathy domain (Stanley et al., 2013). Finally, PPI-Boldness was also significantly and uniquely associated with antisocial behavior, as well as alcohol and marijuana use in the community sample.

\section{PPI-Meanness}

The PPI-Meanness scale was strongly associated with TriPM Meanness, and to a lesser degree, TriPM Disinhibition in both samples; this was consistent with Hall et al.'s (2014) findings. In addition, and consistent with previous triarchic psychopathy research (Drislane et al., 2014; Sellbom \& Phillips, 2013), PPI-Meanness was associated with the largest effect size prediction of the LSRP Egocentricity and Callous scales. Moreover, this PPI Triarchic scale was also associated with PCL-R Total, Factor 2, and Facet 4 scores at the zeroorder level. Surprisingly, although associated with the largest correlation and standardized beta weight in the prediction of PCL-R Facet 2 (Affective), as expected and consistent with Hall et al.'s findings, these did not reach statistical significance $(p=.02)$ at our conservative alpha level. In terms of personality correlates, PPI-Meanness was most strongly associated with PID-5 Antagonism relative to the other PPI-Tri scales, as consistent with previous work with the TriPM (Anderson et al., in press; Strickland et al., 2013), but also Detachment in the community sample, which is consistent with meanness as a reflection of agentic disaffiliation (Patrick et al., 2009). This PPI Triarchic scale was also the best predictor of three of the four IRI subscales directly reflecting deficient empathic functioning, which is a core feature of the meanness construct (Patrick et al., 2009). Finally, PPI-Meanness was the only significant predictor of NPD criterion counts as well as contributed uniquely to the prediction of ASPD in the community sample. In terms of discriminant validity, PPIMeanness had moderate zero-order correlations with various indicators of disinhibitory traits (LSRP Antisocial, PID-5 Disinhibition), but these became nonsignificant in the regression analyses where PPI-Disinhibition was also a predictor.

\section{PPI-Disinhibition}

As expected, the PPI-Disinhibition scale was associated with the largest effect size in predicting the TriPM Disinhibition scale, and contributed to a small degree to the prediction of TriPM Meanness, which is consistent with previous findings (Hall et al., 2014). Scores on PPI-Disinhibition were also modestly inversely correlated with TriPM Boldness in the prison, but not community, sample (Fisher's $z=2.17, p=$ 
.03). In terms of PCL-R scores, it had moderate correlations with Factor 2 and Facet 3, which is also consistent with being most strongly associated with the LSRP Antisocial facet scale. From a personality perspective, PPI-Disinhibition showed large correlations with PID-5 Disinhibition, but also contributed uniquely to the prediction of all five PID-5 domains in the regression analyses (see also Strickland et al., 2013). The magnitude of the correlation between PPI-Disinhibition and PID-5 Disinhibition was stronger in the prison than community sample (Fisher's $z=-3.31, p<.001$ ). In addition, positive correlations between PPI-Disinhibition and PID-5 Negative Affectivity, Psychoticism, and Detachment were also observed. Furthermore, consistent with previous research on Triarchic disinhibition (Hall et al., 2014; Sellbom \& Phillips, 2013), this PPI Triarchic scale was significantly and uniquely associated with various predictors of antisociality and substance use in both community and prison samples.

\section{DISCUSSION}

This study replicates and extends Hall and colleagues' (2014) promising work on developing PPI and PPI-R Triarchic scales, and extends the validity of these scales to those scored on the PPI-R. The results reported here indicate promising construct validity for the these PPI-based scales as their convergent and discriminant associations mirror those of both previous work (Hall et al., 2014) and those reported with other triarchic measures, including the TriPM (e.g., Drislane et al., 2014; Sellbom \& Phillips, 2013; Stanley et al., 2013).

Some specific findings warrant further discussion. Although the association between boldness and substance use is a relatively novel finding (but see Hicks, Iacono, \& McGue, 2014; Hicks et al., 2013), as these are typically most strongly associated with disinhibition (Krueger, Markon, Patrick, Benning, \& Kramer, 2007), this adds to the literature indicating that this psychopathy construct is associated with maladaptive behaviors in addition to adaptive functioning (cf. Miller \& Lynam, 2012). Indeed, this community sample exhibited a greater range of boldness variance, perhaps because of the recruitment strategy employed, as opposed to samples with a greater range and level of disinhibition (e.g., criminal samples).

In terms of unexpected findings, most surprising was the large association with PID-5 Psychoticism; however, Eysenck (e.g., Eysenck \& Eysenck, 1976) frequently argued that disinhibition and psychosis fell on the same continuum, with the former indicating a progression toward the latter. Another possible explanation is that psychoticism includes significant general maladjustment variance in addition to schizotypy (Hopwood et al., 2012). Moderate associations with PID-5 Negative Affectivity and Detachment, albeit not conceptually indicated, are nonetheless consistent with previous research (Strickland et al., 2013).

\section{Implications}

Despite very different samples (community members vs. male prisoners), the pattern of associations with criterion measures was highly consistent for triarchic scales developed from the PPI and PPI-R. This provides strong support that the PPI-R-Tri scales measure the constructs of the triarchic model in largely the same way as the original PPI-Tri scales developed by Hall and colleagues (2014). These findings are important, as they further demonstrate the utility of the PPI and PPI-R in capturing these psychopathy constructs and allows for a broader examination of the triarchic model of psychopathy given the extensive range of studies that have employed the PPI and PPI-R in a variety of psychopathy research focused on neuroscience, behavioral correlates, and applied settings (e.g., forensic, correctional; see, e.g., Sellbom, Lilienfeld, Fowler, \& McCrary, in press, for a review). Additionally, because the PPI-Tri scales measure psychopathic tendencies in trait-dimensional terms without reference to antisocial behavior, they could be used in future investigations evaluating crime prediction avoiding the potential issue of criterion contamination that is sometimes raised for studies using the PCL-R (Cooke, Michie, Hart, \& Clark, 2004). Furthermore, these findings further indicate that a realignment of the PPI and PPI-R items to reflect the triarchic constructs provide for more distinct measurement and separation of the important meanness construct, which many scholars would contend represents the core trait domain of psychopathy in both childhood (i.e., callous-unemotional traits; e.g., Barry et al., 2000) and adulthood (e.g., antagonism; see Derefinko \& Lynam, 2013).

Findings of this study are also consistent with an underlying goal of the triarchic model, which is to link the phenotypic components of psychopathy to broader models of personality and psychopathology (Patrick et al., 2009). Indeed, PPI-Meanness was strongly associated with symptoms of NPD and ASPD (along with PPI-Disinhibition), suggesting that antagonistic personality traits represent a common liability underlying Cluster B personality disorders (Kernberg, 1989). Critically, however, this study also replicates important findings that boldness distinguishes psychopathy from related disorders, as scores on PPIBoldness predicted unique variance in Factor 1 and Facet 1 of the PCL-R, but not symptoms of ASPD (Venables, Hall, \& Patrick, 2014; Wall, Wygant, \& Sellbom, in press). Likewise, this study is consistent with previous reports demonstrating that the LSRP measures psychopathy somewhat differently than the PCL-R, as it does not contain variance related to boldness (Drislane et al., 2014; Sellbom \& Phillips, 2013). Thus, scores on the LSRP might be more reflective of general externalizing or antisocial tendencies than primary psychopathy, which also emphasizes social dominance embodied by boldness.

\section{Limitations and Future Directions}

Despite these important implications, our findings must be considered in light of some limitations. The prison sample size was relatively small, especially given our conservative alpha level, and only consisted of male inmates; future work needs to replicate these findings in a female inmate sample. We also did not have access to interrater reliability information for the SCID-II in either sample or the background interview in the community sample; as such, we do not know the degree to which those results are attenuated due to measurement error. Nevertheless, the pattern of findings is consistent with both conceptual expectations and previous empirical work. 
In addition to replicating the initial work on the PPI Triarchic scales (Hall et al., 2014), the findings reported here are in line with recent research aimed at elucidating the triarchic model of psychopathy in existing assessment instruments (e.g., Drislane et al., in press). Future work should continue to explore this approach with other omnibus personality inventories, such as the Minnesota Multiphasic Personality Inventory-2-RF (Ben-Porath \& Tellegen, 2008), which also exhibit substantial clinical utility, thus bridging psychopathology research and clinical assessment.

\section{ACKNOWLEDGMENTS}

We would like to thank Jaime Anderson, Kathryn Applegate, Adam Crighton, Brandee Goodwin, Cody Ison, Jessica Jacobs, Alexandria Johnson, Rebecca Kastner, Jade Petty, Rachel Rock, Jennifer Stanley, Katara West, Courtney Welsh, and Christopher Wiggins for their assistance in data collection. We would also like to thank the Kentucky Department of Corrections and the staff at Northpoint Training Center for allowing the research to take place in their facility. None of the opinions or conclusions expressed in this article reflects any official policy or position of the Kentucky Department of Corrections.

\section{FUNDING}

This research was supported by a research grant from the University of Minnesota Press awarded to Martin Sellbom and a Major Project Award from the University Research Committee at Eastern Kentucky University awarded to Dustin B. Wygant.

\section{REFERENCES}

Alterman, A. I., McDermott, P. A., Cacciola, J. S., \& Rutherford, M. J. (2003). Latent structure of the Davis Interpersonal Reactivity Index in methadone maintenance patients. Journal of Psychopathology and Behavioral Assessment, 25, 257-265.

American Psychiatric Association. (2013). Diagnostic and statistical manual of mental disorders (5th ed.). Washington, DC: Author.

Anderson, J. L., Sellbom, M., Bagby, M., Quilty, L. C., Veltri, C. O. C., Markon, K. E., \& Krueger, R. F. (2013). Examining the MMPI-2-RF PSY-5 scales for the assessment of $D S M-5$ personality trait dimensions. Assessment, 20, 286-294.

Anderson, J. L., Sellbom, M., Wygant, D. B., Salekin, R. T., \& Krueger, R. F. (in press). Examining the associations between DSM-5 Section 3 antisocial personality disorder and psychopathy in community and university samples. Journal of Personality Disorders.

Barry, C. T., Frick, P. J., DeShazo, T. M., McCoy, M., Ellis, M., \& Loney, B. R. (2000). The importance of callous-unemotional traits for extending the concept of psychopathy to children. Journal of Abnormal Psychology, 109, 335-340.

Belmore, M. F., \& Quinsey, V. L. (1994). Correlates of psychopathy in a noninstitutional sample. Journal of Interpersonal Violence, 9, 339-349.

Ben-Porath, Y. S., \& Tellegen, A. (2008). MMPI-2-RF: Manual for administration, scoring and interpretation. Minneapolis: University of Minnesota Press.

Benning, S. D., Patrick, C. J., Hicks, B. M., Blonigen, D. M., \& Krueger, R. F. (2003). Factor structure of the Psychopathic Personality Inventory: Validity and implications for clinical assessment. Psychological Assessment, 15, 340-350.

Cooke, D. J., Michie, C., Hart, S. D., \& Clark, D. A. (2004). Reconstructing psychopathy: Clarifying the significance of antisocial and socially deviant behavior in the diagnosis of psychopathic personality disorder. Journal of Personality Disorders, 18, 337-357.

Davis, M. H. (1983). Measuring individual differences in empathy: Evidence for a multidimensional approach. Journal of Personality and Social Psychology, 44, 113-126.

DeMatteo, D., Heilbrun, K., \& Marczyk, G. (2006). An empirical investigation of psychopathy in a noninstitutionalized and noncriminal sample. Behavioral Sciences \& the Law, 24, 133-146.

Derefinko, K., \& Lynam, D. R. (2013). Psychopathy from the perspective of the Five-factor model of personality. In T.A. Widiger \& P.T. Costa (Eds.), Personality disorders and the Five-factor model of personality (3rd ed., pp. 103-117). Washington, DC: American Psychological Association.

Drislane, L. E., Brislin, S., Kendler, K., Andershed, H., Larsson, H., \& Patrick, C. J. (in press). A triarchic model analysis of the Youth Psychopathic Traits Inventory. Journal of Personality Disorders.

Drislane, L. E., Patrick, C. J., \& Arsal, G. (2014). Clarifying the content coverage of differing psychopathy inventories through reference to the Triarchic Psychopathy Measure. Psychological Assessment, 26, 350-362. doi:10.1037/a0035152

Eysenck, H. J., \& Eysenck, S. B. G. (1976). Psychoticism as a dimension of personality. New York, NY: Plenum.

First, M. B., Gibbon, M., Spitzer, R. L., Williams, J. B. W., \& Benjamin, L. S. (1997). SCID-II personality questionnaire. Washington, DC: American Psychiatric Press.

Hall, J. R., Drislane, L. E., Patrick, C. J., Morano, M., Lilienfeld, S. O., \& Poythress, N. G. (2014). Development and validation of triarchic construct scales from the Psychopathic Personality Inventory. Psychological Assessment, 26, 447-461. doi:10.1037/a0035665

Hare, R. D. (2003). The Hare Psychopathy Checklist-Revised (2nd ed.). Toronto, Canada: Multi-Health Systems.

Hare, R. D., \& Neumann, C. S. (2008). Psychopathy as a clinical and empirical construct. Annual Review of Clinical Psychology, 4, 217-246.

Hicks, B. M., Iacono, W. G., \& McGue, M. (2014). Identifying childhood characteristics that underlie pre-morbid risk for substance use disorders: Socialization and boldness. Development and Psychopathology, 26, 141157

Hicks, B. M., Johnson, W., Durbin, C. E., Blonigen, D. M., Iacono, W. G., \& McGue, M. (2013). Gene-environment correlation in the development of adolescent substance abuse: Selection effects of child personality and mediation via contextual risk factors. Development and Psychopathology, 25, $119-132$.

Hirschi, T., Hindelang, M. J., \& Weis, J. G. (1980). The status of self-report measures. In M. W. Klein \& K. S. Teilman (Eds.), Handbook of criminal justice evaluation (pp. 473-488). Beverly Hills, CA: Sage.

Hopwood, C. J., Thomas, K. M., Markon, K. E., Wright, A. G. C., \& Krueger, R. F. (2012). $D S M-5$ personality traits and $D S M-I V$ personality disorders. Journal of Abnormal Personality, 121, 424-432.

Kernberg, O. F. (1989). The narcissistic personality disorder and the differential diagnosis of antisocial behavior. Psychiatric Clinics of North America, $12,553-570$.

Krueger, R. F., Derringer, J., Markon, K. E., Watson, D., \& Skodol, A. E. (2012). Initial construction of a maladaptive personality trait model and inventory for DSM-5. Psychological Medicine, 42, 1879-1890.

Krueger, R. F., Markon, K. E., Patrick, C. J., Benning, S. D., \& Kramer, M. D. (2007). Linking antisocial behavior, substance use, and personality: An integrative quantitative model of the adult externalizing spectrum. Journal of Abnormal Psychology, 116, 645-666.

Levenson, M. R., Kiehl, K. A., \& Fitzpatrick, C. M. (1995). Assessing psychopathic attributes in a non-institutionalized population. Journal of Personality and Social Psychology, 68, 151-158.

Lilienfeld, S. O., \& Andrews, B. P. (1996). Development and preliminary validation of a self report measure of psychopathic personality traits in noncriminal populations. Journal of Personality Assessment, 66, 488-524.

Lilienfeld, S. O., Patrick, C. J., Benning, S. D., Berg, J., Sellbom, M., \& Edens, J. F. (2012). The role of fearless dominance in psychopathy: Confusions, controversies, and clarifications. Personality Disorders: Theory, Research, and Treatment, 3, 327-340. 
Lilienfeld, S. O., \& Widows, M. R. (2005). Psychopathic Personality Inventory-Revised professional manual. Lutz, FL: Psychological Assessment Resources.

Lobbestael, J., Leurgans, M., \& Arntz, A. (2011). Inter-rater reliability of the Structured Clinical Interview for DSM-IV Axis I Disorders (SCID I) and Axis II Disorders (SCID II). Clinical Psychology and Psychotherapy, 18, 75-79.

Lynam, D. R., \& Derefinko, K. J. (2006). Psychopathy and personality. In C. J. Patrick (Ed.), Handbook of psychopathy (pp. 133-155). New York, NY: Guilford.

Lynam, D. R., Whiteside, S., \& Jones, S. (1999). Self-reported psychopathy: A validation study. Journal of Personality Assessment, 73, 110-132.

Maffei, C., Fossati, A., Agostoni, I., Barraco, A., Bagnato, M., Deborah, D., .., \& Petrachi, M. (1997). Interrater reliability and internal consistency of the structured clinical interview for DSM-IV Axis II personality disorders (SCID-II), version 2.0. Journal of Personality Disorders, $11,279-284$.

Marion, B. E., Sellbom, M., Salekin, R. T., Toomey, J. A., Kucharski, L. T., \& Duncan, S. (2013). An examination of the association between psychopathy and dissimulation using the MMPI-2-RF validity scales. Law and Human Behavior, 37, 219-230.

Marks, I. M., \& Mathews, A. M. (1979). Brief standard self-rating for phobic patients. Behavior Research and Therapy, 17, 263-267.

Miller, J. D., \& Lynam, D. R. (2012). An examination of the Psychopathic Personality Inventory's nomological network: A meta-analytic review. Personality Disorders: Theory, Research, and Treatment, 3, 305-326.

Neumann, C. S., Malterer, M. B., \& Newman, J. P. (2008). Factor structure of the Psychopathic Personality Inventory (PPI): Findings from a large incarcerated sample. Psychological Assessment, 20, 169-174.

Oei, T. P. S., Moylan, A., \& Evans, L. (1991). Validity and clinical utility of the Fear Questionnaire for anxiety-disorder patients. Psychological Assessment, 3, 391-397.

Patrick, C. J. (2010). Operationalizing the triarchic conceptualization of psychopathy: Preliminary description of brief scales for assessment of boldness, meanness, and disinhibition. Unpublished test manual, Florida State University, Tallahassee, FL.

Patrick, C. J., Drislane, L. E., \& Strickland, C. (2012). Conceptualizing psychopathy in triarchic terms: Implications for treatment. International Journal of Forensic Mental Health, 11, 253-266.

Patrick, C. J., Fowles, D. C., \& Krueger, R. F. (2009). Triarchic conceptualization of psychopathy: Developmental origins of disinhibition, boldness, and meanness. Development and Psychopathology, 21, 913-938.

Raine, A., Lencz, T., Bihrle, S., LaCasse, L., \& Colletti, P. (2000). Reduced prefrontal gray matter volume and reduced autonomic activity in antisocial personality disorder. Archives of General Psychiatry, 57, 119-127.

Sellbom, M. (2011). Elaborating on the construct validity of the Levenson Self-Report Psychopathy Scale in incarcerated and non-incarcerated samples. Law and Human Behavior, 35, 440-451.

Sellbom, M., Anderson, J. L., \& Bagby, R. M. (2013). Assessing DSM-5 Section III personality traits and disorders with the MMPI-2-RF. Assessment, 20, 709-722.
Sellbom, M., Ben-Porath, Y. S., Patrick, C. J., Wygant, D. B., Gartland, D. M., \& Stafford, K. P. (2012). Development and construct validation of MMPI-2-RF measures assessing Global Psychopathy, FearlessDominance, and Impulsive-Antisociality. Personality Disorders: Theory, Research, and Treatment, 3, 17-38.

Sellbom, M., Lilienfeld, S. O., Fowler, K., \& McCrary, K. L. (in press). The self-report assessment of psychopathy: Challenges, pitfalls, and promises. In C. J. Patrick (Ed.), Handbook of psychopathy (2nd ed.). New York, NY: Guilford.

Sellbom, M., \& Phillips, T. R. (2013). An examination of the triarchic conceptualization of psychopathy in incarcerated and non-incarcerated samples. Journal of Abnormal Psychology, 122, 208-214.

Sellbom, M., Smid, W., De Saeger, H., Smit, N., \& Kamphuis, J. H. (2014). Mapping the Personality Psychopathology Five domains onto DSM-IV personality disorders in Dutch clinical and forensic samples: Implications for DSM-5. Journal of Personality Assessment, 96, 185-191.

Sellbom, M., \& Verona, E. (2004, September). Differential neuropsychological mechanisms for two psychopathy factors. Poster presented at the 19th annual meeting for the Society for Research in Psychopathology, St. Louis, MO.

Skeem, J. L., Polaschek, D. L. L., Patrick, C. J., \& Lilienfeld, S. O. (2011). Psychopathic personality: Bridging the gap between scientific evidence and public policy. Psychological Science in the Public Interest, 12, 95-162.

Stanley, J. H., Wygant, D. B., \& Sellbom, M. (2013). Elaborating on the construct validity of the Triarchic Psychopathy Measure in a criminal offender sample. Journal of Personality Assessment, 95, 343-350.

Strickland, C. M., Drislane, L. E., Lucy, M., Krueger, R. F., \& Patrick, C. J. (2013). Characterizing psychopathy using DSM-5 personality traits. Assessment, 20, 327-338.

Thomas, K. M., Yalch, M. M., Krueger, R. F., Wright, A. G., Markon, K. E., \& Hopwood, C. J. (2013). The convergent structure of DSM-5 personality trait facets and five-factor model trait domains. Assessment, 20, 308-311.

Venables, N. C., Hall, J. R., \& Patrick, C. J. (2014). Differentiating psychopathy from antisocial personality disorder: A triarchic model perspective. Psychological Medicine, 44, 1005-1013.

Wall, T. D., Sellbom, M., \& Goodwin, B. E. (2013). Examination of intelligence as a compensatory factor in non-criminal psychopathy in a non-incarcerated sample. Journal of Psychopathology and Behavioral Assessment, $35,450-459$.

Wall, T., Wygant, D. B., \& Sellbom, M. (in press). Boldness explains a key difference between psychopathy and antisocial personality disorder. Psychiatry, Psychology, and Law.

Widom, C. S. (1977). A methodology for studying noninstitutionalized psychopaths. Journal of Consulting and Clinical Psychology, 45, 674-683.

Widom, C. S., \& Newman, J. P. (1985). Characteristics of non-institutionalized psychopaths. In D. P. Farrington \& J. Gunn (Eds.), Aggression and dangerousness (pp. 57-80). New York, NY: Wiley. 